\title{
Phase-shifting Mechanisms in the Mammalian Circadian System: New Light on the Carbachol Paradox
}

\author{
Christopher S. Colwell, Claire M. Kaufman, and Michael Menaker \\ NSF Center for Biological Timing, Department of Biology, University of Virginia, Charlottesville, Virginia 22901
}

\begin{abstract}
A variety of evidence now suggests that excitatory amino acid receptors mediate the effects of light on the circadian system of mammals. However, the ACh agonist carbachol is the only agent that has been reported to "mimic" the phase-shifting effects of light in vivo. Because the other published evidence for the involvement of ACh in light-mediated phase shifts is weak, we have referred to this situation as "the carbachol paradox." In the present study, we found that the administration of NMDA receptor antagonists could prevent carbachol-induced phase shifts of the circadian rhythm of wheel-running activity recorded from the hamster. In addition, we found that carbachol-induced phase shifts, unlike those produced by light, are not accompanied by induction of Fos-like immunoreactivity in the suprachiasmatic nucleus (SCN). Our data are simply explained by the assumption that the intraventricular administration of carbachol causes phase shifts through a pathway distinct from that of light. Alternatively, if carbachol is acting via the light input pathway, then it must do so by a mechanism independent of Fos induction in the SCN. In either case, elucidating the mechanisms by which carbachol acts in the circadian system may provide novel insights into the cellular events by which phase shifts are generated.
\end{abstract}

[Key words: hamster, circadian rhythm, excitatory amino acids, ACh, CCP (2-carboxypiperazin-4-yl)-propyl-1-phosphonic acid), dizocilpine, carbachol]

Circadian rhythms are endogenously generated oscillations with periods of approximately $24 \mathrm{hr}$. The physiological system responsible for these rhythms can be modeled in three parts: (1) an input pathway by which environmental signals are transmitted to (2) a pacemaker, which is coupled to the processes it controls by (3) an output pathway. In order to function adaptively, the circadian system must be synchronized (or entrained) with appropriate phase to the $24 \mathrm{hr}$ period of the environment in which the organism lives. The daily light-dark cycle, acting through light-induced advances and delays of the endogenous oscillation, is the dominant environmental signal responsible for this entrainment. A major goal of circadian rhythm research is to understand the cellular mechanisms by which light signals phase shift endogenous circadian oscillators.

\footnotetext{
Received May 26, 1992; revised Sept. 30, 1992; accepted Oct. 6, 1992.

We thank Dr. N. Wayne for comments on an early draft of the manuscript. This work was supported by NIH Grant HD13162 to M.M. and NIMH Grant MH09987-01 to C.S.C. C.M.K. and C.S.C. were also supported by the NSF Center for Biological Timing. C.S.C. is the recipient of the FESN fellowship on "Circadian Rhythms."

Correspondence should be addressed to C. S. Colwell, Mental Retardation Research Center, University of California at Los Angeles, 760 Westwood Plaza, Los Angeles, CA 90024-1759.

Copyright (C) 1993 Society for Neuroscience $0270-6474 / 93 / 131454-06 \$ 05.00 / 0$
}

In mammals, the suprachiasmatic nucleus (SCN) functions as the dominant pacemaker of the circadian system. The effects of light on the SCN are mediated by unknown photoreceptors located in the retina (Nelson and Zucker, 1981; Foster et al., 1991) that project to the hypothalamus, at least in part, via a monosynaptic fiber tract known as the retinohypothalamic tract (RHT) (Moore, 1983).

A variety of evidence suggests an excitatory amino acid (EAA) is a transmitter at the RHT/SCN synaptic connection. There is evidence that both the NMDA and non-NMDA receptor subclasses of EAA receptors are involved. Electrophysiological studies using an in vitro hypothalamic slice preparation that contains the SCN suggest a role for both receptor types (Shibata et al., 1986; Cahill et al., 1989; Mason and Rusak, 1990; Ito et al., 1991; Kim and Dudek, 1991). For example, Kim and Dudek (1991) found that EPSPs recorded intracellularly in the SCN in response to optic nerve stimulation were blocked by both NMDA and non-NMDA receptor antagonists. Recent anatomical evidence suggests that EAA-immunoreactive fibers innervate the SCN (Moffett et al., 1990; Van den Pol, 1991). Finally, pharmacological studies have implicated both NMDA and nonNMDA receptor types in the photic regulation of the circadian system of rodents (Colwell et al., 1990, 1991; Rea et al., 1991; Takeuchi et al., 1991; Colwell and Menaker, 1992).

It has been suggested that ACh may also play a role in the light-input pathway. The intraventricular administration of the ACh agonist carbachol causes phases shifts that have been reported to mimic the effects of light on the mammalian circadian system (Zatz and Brownstein, 1979; Zatz and Herkenham, 1981; Earnest and Turek, 1983, 1985; Wee et al., 1992; but also see Meijer et al., 1988, for alternative view). Additionally, mecamylamine, an antagonist to the ion channels activated by $\mathrm{ACh}$, has been reported to prevent light-induced phase shifts (Keefe et al., 1987). Further, electrophysiological studies indicate that some SCN neurons show similar responses to light and cholinergic agents (Nishino and Koizumi, 1977; Miller et al., 1987). Finally, the ACh content of the SCN increases after a light pulse (Murakami et al., 1984). Nevertheless, the neuroanatomical site of action and pharmacological specificity of carbachol remain unclear (see Rusak and Bina, 1990, for discussion).

The protein Fos (the product of the c-fos gene) is induced in neurons in response to a number of stimuli including EAAs and carbachol (Morgan and Curran, 1991). Recent work has shown that light causes an increase in Fos-like immunoreactivity (FosLI) and c-fos mRNA in the SCN (Rea, 1989; Aronin et al., 1990; Earnest et al., 1990; Kornhauser et al., 1990; Rusak et al., 1990; Colwell and Foster, 1992). In addition, the induction of Fos in the SCN by light is correlated in both its phase dependence and threshold with the ability of the same light treatment to phase shift the circadian oscillator (Kornhauser et al., 1990). Fur- 
thermore, EAA receptor antagonists inhibit the photic induction of Fos in the SCN (Abe et el., 1991, 1992; Colwell and Foster, 1991; Rea et al., 1991) while the administration of the EAA agonist NMDA can cause an induction of Fos in the SCN (Ebling et al., 1991). Although it is not clear whether Fos plays a causal role in light-induced phase shifts of the circadian system, previous work does suggest that Fos-induction can be used as a cellular marker of photic input to the SCN.

To elucidate the effects of carbachol and the possible role of ACh in mediating light-induced phase shifts of the circadian system, we conducted experiments to determine whether the administration of the NMDA receptor antagonists dizocilpine (MK-801) and 3-(2-carboxypiperazin-4-yl)-propyl-1-phosphonic acid (CPP) could prevent carbachol-induced phase shifts of the circadian rhythm of wheel-running activity. We then asked whether intraventricular injections of carbachol caused induction of Fos-LI in the SCN. We reasoned that if ACh acts at any point along the light input pathway to the circadian system then EAA receptor antagonists should prevent carbachol-induced phase shifts and carbachol itself should cause an induction of Fos-LI in the SCN.

\section{Materials and Methods}

Animals. Male golden hamsters (Mesocricetus auratus, LVG-outbred), obtained from Lakeview, Charles River at 10 weeks of age, were housed individually and their wheel-running activity recorded. The animals were exposed to a $14 \mathrm{hr}: 10 \mathrm{hr}$ light-dark cycle for 2 weeks. A cannula was then stereotaxically placed into the third ventricle under sodium pentobarbital anesthesia (coordinates: $0.6 \mathrm{~mm}$ anterior to bregma, on midline, $8.1 \mathrm{~mm}$ ventral). The cannula was fixed to the skull with dental acrylic and three screws. A wire was inserted in the cannula to keep it open, and the hole was protected by a removable cap. The placement of the cannula was later verified histologically.

Two to three weeks after cannulation, the animals were placed in constant dark (DD) for $10 \mathrm{~d}$ to assess their free-running activity pattern. Hamsters remained in DD and were subjected to one of four treatments: (1) injection of vehicle alone, (2) injection of carbachol, (3) injection of EAA receptor antagonist alone, (4) injection of EAA receptor antagonist plus carbachol. The carbachol treatments were delivered $8 \mathrm{hr}$ after the onset of activity [i.e., circadian time (CT) 20.0; onset of activity is defined as CT 12 for nocturnal animals] when light would normally induce a phase advance. Animals used for immunocytochemistry were killed 60 min after treatment. Otherwise, following each treatment, the animals were allowed to free-run undisturbed in DD for $10 \mathrm{~d}$ before receiving another treatment. No animal was treated more than twice.

Carbachol (an acetylcholine agonist; 0.05 or $0.005 \mathrm{M}$ ) and CPP (an NMDA receptor antagonist; $0.1 \mathrm{~mm}$ ) were solubilized in artificial cerebral spinal fluid and were administered via the cannula at CT 20. Injection volumes were $1.0 \mu 1$ of solution. Dizocilpine (MK-801; an NMDA receptor antagonist; $4.8 \mathrm{mg} / \mathrm{kg}$ ) in dimethyl sulfoxide was administered by intraperitoneal injection at CT 19. All drugs were purchased from Research Biochemicals Incorporated, Natick, MA. The light stimulus used to induce Fos-LI was a 15 min pulse of monochromatic light $(515 \mathrm{~nm})$ at an intensity of $1.5 \times 10^{-1} \mu \mathrm{W} / \mathrm{cm}^{2}$ at CT 20 . The apparatus used to produce the stimulus has been previously described (Foster et al., 1991). The stimulus parameters (duration, irradiance, and wavelength) were chosen to produce submaximal phase shifts. Stimulus intensity (irradiance) was measured before each trial with a radiometer (United Detector Technologies, Hawthorne, CA). Following the light pulse, the hamsters were returned to constant darkness until the time of perfusion. All handling and treatment of animals was carried out in complete darkness with the aid of an infrared viewer (FJW Industries, Elgin, IL).

Analysis of wheel-running behavior. Phase shifts in the activity rhythm were determined by measuring the phase difference between eye-fitted lines connecting the onset of activity for a period of $7 \mathrm{~d}$ before and 10 $\mathrm{d}$ after an experimental manipulation. In order to estimate the steady state phase shifts produced, $4 \mathrm{~d}$ of data after treatments that caused phase advances were excluded from the analysis. In other respects, the method for calculating phase shifts was the same as has been reported elsewhere (Takahashi et al., 1984). The phase-shifting effects of a treatment were considered to be significant when the $95 \%$ confidence interval of the group mean did not overlap zcro. Differences between trcatment groups were evaluated using a Kruskal-Wallis one-way analysis of variance, followed by a Mann-Whitney $U$ test where appropriate. Values were considered significantly different if $P<0.05$. In the text, values are shown as means \pm SEM; and phase advances are shown as positive values while phase delays are shown as negative values.

Tissue preparation and immunocytochemistry. For perfusion, animals were removed from their light-tight boxes and anesthetized with a lethal dose of halothane by inhalation in darkness. Then, under dim red light, the hamsters were perfused intracardially first with $30-40 \mathrm{ml}$ of physiological saline $(0.9 \% \mathrm{w} / \mathrm{v})$ containing $150 \mathrm{IU}$ of heparin $/ 10 \mathrm{ml}$, followed by $300 \mathrm{ml}$ of $2 \% \mathrm{w} / \mathrm{v}$ formaldehyde in $0.1 \mathrm{M}$ phosphate-buffered saline (PBS; pH 7.2-7.4) with picric acid (15\%). After perfusion, the brains were removed and postfixed overnight at $4^{\circ} \mathrm{C}$. Serial frontal sections were cut at $50 \mu \mathrm{m}$ into PBS using a cryostat.

Free-floating sections were transferred to a solution of normal goat serum (1:30 in PBS with $2 \%$ Triton) for $30 \mathrm{~min}$ then directly into primary antiserum. The Fos antiserum used in this study was an anti-Fos (4-17) rabbit polyclonal antiserum purchased from Oncogene Science (Uniondale, NY). The antibody was used at a dilution of $1: 250$ for 72 hr at $4^{\circ} \mathrm{C}$. The sites of the antibody:antigen binding were visualized with an avidin-biotin-peroxidase procedure (Elite ABC kit, Vector Labs, Burlingame, CA). Sections were washed in Tris buffer ( $\mathrm{pH} 7.2,15 \mathrm{~min}$ ) before incubation for $6 \mathrm{~min}$ in $0.025 \%$ diaminobenzidine (DAB) containing $0.003 \%(\mathrm{w} / \mathrm{v})$ peroxide. Sections mounted on gelatin-coated slides were dehydrated through graded alcohols into xylene and left overnight before being rehydrated to distilled water and immersed in $0.2 \%(\mathrm{w} / \mathrm{v})$ osmium tetroxide solution $(2 \mathrm{~min})$ to intensify the DAB reaction. Histological analysis and photomicrographs utilized a Zeiss Axiophot photomicrographic system.

To minimize variability, we used a standard immunocytochemical protocol, which kept incubation times constant, and used a single batch of antisera and other reagents. In addition, we processed hamster tissue for immunocytochemistry in large groups of 10 or 12 brains, which therefore constituted a self-contained experiment. Two types of immunocytochemical controls were performed. Tissue sections were processed for immunocytochemistry; however, the primary antiserum was replaced with normal nonimmune rabbit serum. Sections were also incubated with "preabsorbed" primary antibody. To preabsorb the antibody, $1 \mu \mathrm{g}$ of peptide (obtained from the suppliers of the antisera) was added to $1 \mathrm{ml}$ of diluted antibody and incubated at $4^{\circ} \mathrm{C}$ overnight before being added to the brain sections.

Analysis of Fos immunostaining. A series of immunostained sections was counterstained with toluidine blue in order to define Fos immunostaining within the histological borders of the SCN. Noncounterstained sections were observed by phase-contrast microscopy to confirm the distribution of Fos staining within the SCN. Camera lucida drawings of Fos-stained perikarya within the SCN were made. It was possible to identify and count immunostained perikarya accurately.

\section{Results}

The intraventricular administration of carbachol $(0.05 \mathrm{M})$ at CT 20 caused a phase advance of $194.4 \pm 36.7 \mathrm{~min}(N=9$; range, 45-365 min, with six of nine values $>180 \mathrm{~min}$. Examples of carbachol-induced phase advances are shown in Figure 1, $A$ and $D$. All of the phase shifts appeared to be completed by the second cycle after administration of the drug. This same dose of carbachol $(0.05 \mathrm{M})$ administered at CT 18 caused a smaller phase advance $(38.6 \pm 19.0 \mathrm{~min}, N=7$, two of seven values $>90$ min). Neither a lower dose of carbachol $(0.005 \mathbf{M})$ nor saline alone administered at CT 20 produced significant phase shifts $(-13.3 \pm 22.3 \mathrm{~min}, N=6 ;-10.0 \pm 5.5 \mathrm{~min}, N=5$; respectively).

The intraperitoneal administration of the NMDA receptor antagonist dizocilpine $(4.8 \mathrm{mg} / \mathrm{kg}$ ) prevented carbachol-induced phase advances in the circadian rhythm of wheel-running activity (Figs. $1 C, 2$ ). Experimental animals that received an injection of dizocilpine $30 \mathrm{~min}$ prior to the administration of 


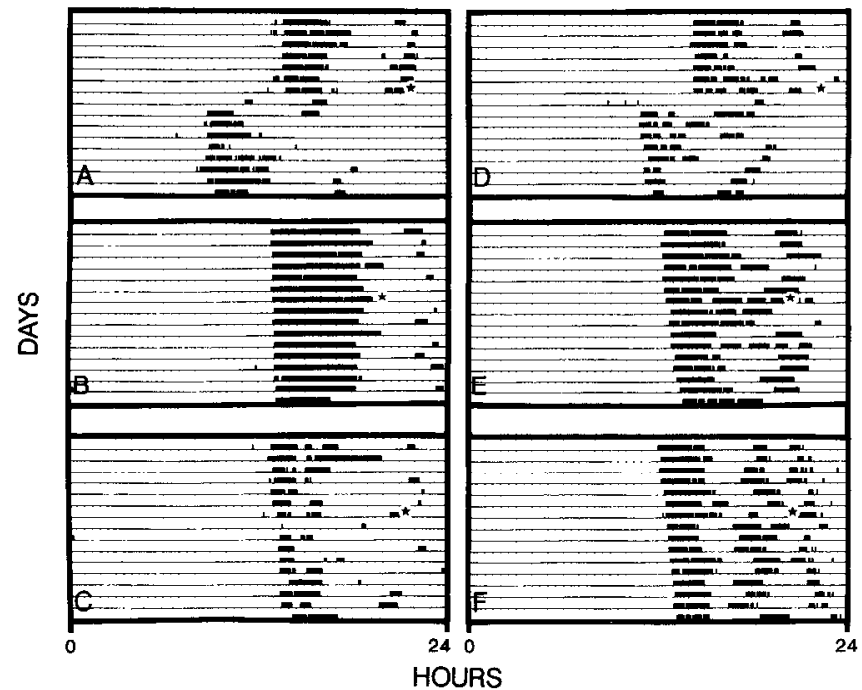

Figure 1. Locomotor activity records from experimental and control animals maintained in DD. Each horizontal line represents the activity record for a $24 \mathrm{hr}$ day, and successive days are plotted from top to hottom. Stars represent the time of light and/or drug treatment. $A$ and $D$, Activity records illustrating the phase-advancing effects of an intraventricular injection of carbachol at CT $20 . B$, Activity record illustrating the lack of effect of an injection of dizocilpine $(4.8 \mathrm{mg} / \mathrm{kg})$ at CT 19.5 on the phase of the circadian rhythm in locomotor activity. $E$, Activity record illustrating that an injection of CPP $(1 \mu \mathrm{l}$ of $0.1 \mathrm{~mm}$ solution) at CT 20 had no effect on the phase of the circadian rhythm of locomotor activity. $C$, Activity record illustrating the blockade of light-induced phase advances by an injection of dizocilpine $(4.8 \mathrm{mg} / \mathrm{kg})$ $30 \mathrm{~min}$ prior to a carbachol treatment at CT $20 . F$, Activity record illustrating the blockage of carbachol-induced phase advance by the coinjection of CPP ( $1 \mu \mathrm{l}$ of $0.1 \mathrm{~mm}$ solution) at CT 20 .

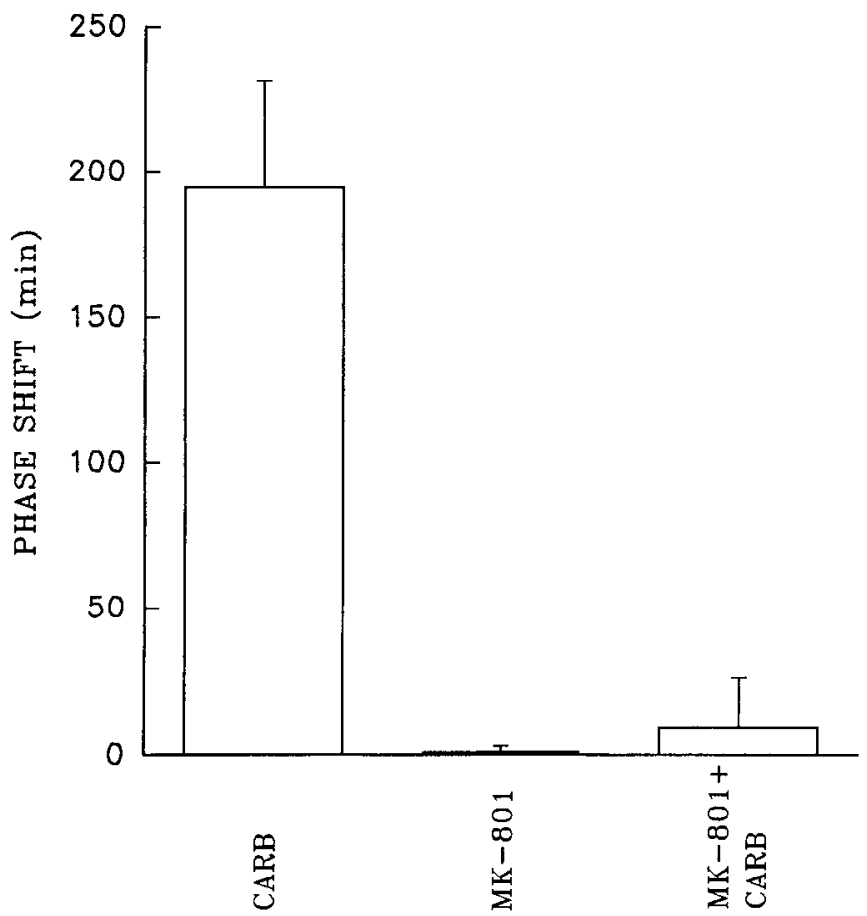

Figure 2. Mean phase shift in the rhythm of locomotor activity of hamsters in DD that received a treatment of either carbachol $(0.05 \mathrm{~mm})$, dizocilpine $(4.8 \mathrm{mg} / \mathrm{kg})$, or dizocilpine + carbachol. Carbachol treatments were delivered at CT 20,8 hr after the onset of activity. The vehicle or drug treatments ( $1 \mu \mathrm{l}$ vol) were delivered $30 \mathrm{~min}$ prior to the carbachol treatment. $N=6-8$ for all points; error bars represent SEM.
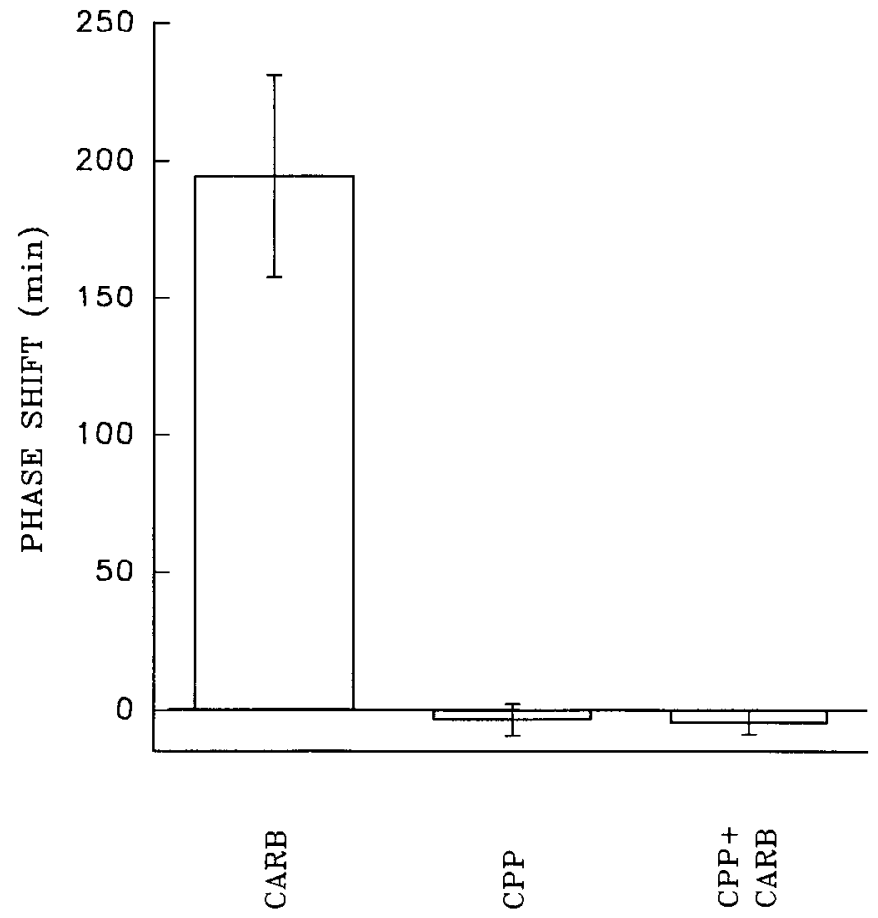

Figure 3. Mean phase shift in the rhythm of locomotor activity in hamsters in DD that received a treatment of either carbachol $(0.05 \mathrm{~mm})$, CPP (0.1 mM), or CPP + carbachol. The treatments were delivered 8 $\mathrm{hr}$ after the onset of activity at CT 20 . For the experimental treatment, CPP and carbachol were coinjected ( $1 \mu \mathrm{l}$ vol $) . N=6-8$ for all points; error bars represent SEM.

carbachol did not show a significant phase shift $(9.2 \pm 17.2$ min, $N=6$ ). This value was significantly different from that of the group treated with carbachol alone $(P<0.001)$. Examples of activity records from experimental and control animals are shown in Figure $1 A-C$. Control injections of saline or dizocilpine alone did not cause significant phase shifts of the circadian rhythm of locomotor activity $(-10.0 \pm 5.5 \mathrm{~min}, N=5 ; 0.8 \pm$ $2.3 \min , N=6$, respectively).

The intraventricular administration of the NMDA receptor antagonist CPP ( $0.1 \mathrm{~mm})$ also prevented carbachol-induced phase advances in the circadian rhythm of wheel-running activity in the hamster (Figs. $1 F, 3$ ). Control intraventricular injections of CPP alone did not cause significant phase shifts of the circadian rhythm of locomotor activity $(-3.3 \pm 5.7 \mathrm{~min}, N=6)$. Experimental animals that received a coinjection of CPP and carbachol did not show a significant phase shift $(-4.3 \pm 4.3 \mathrm{~min}$, $N=7$ ). This value was significantly different from that of the group treated with carbachol alone $(P<0.001)$. Examples of activity records from experimental and control animals are shown in Figure $1 D-F$.

Unlike light, carbachol did not cause an induction of Fos-LI in the SCN of the hamster (Fig. 4). Figure 5 shows a schematic diagram comparing the pattern of Fos-LI in the SCN of a hamster exposed to a $15 \mathrm{~min}$ light pulse al CT 20 with that of a hamster that received an intraventricular injection of carbachol at the same phase. The carbachol injection, which does cause a phase shift in the rhythm of wheel-running activity (Figs. 2, 3), did not cause an induction of Fos-LI in the SCN; the light pulse caused a robust induction of Fos-LI. We also examined Fos-LI in the SCN of animals sampled at various intervals after a carbachol injection at CT 20: $30 \mathrm{~min}(N=3), 60 \mathrm{~min}(N=6)$, $90 \min (N=3)$, and $120 \min (N=4)$. In no case did we find 


\section{LIGHT}

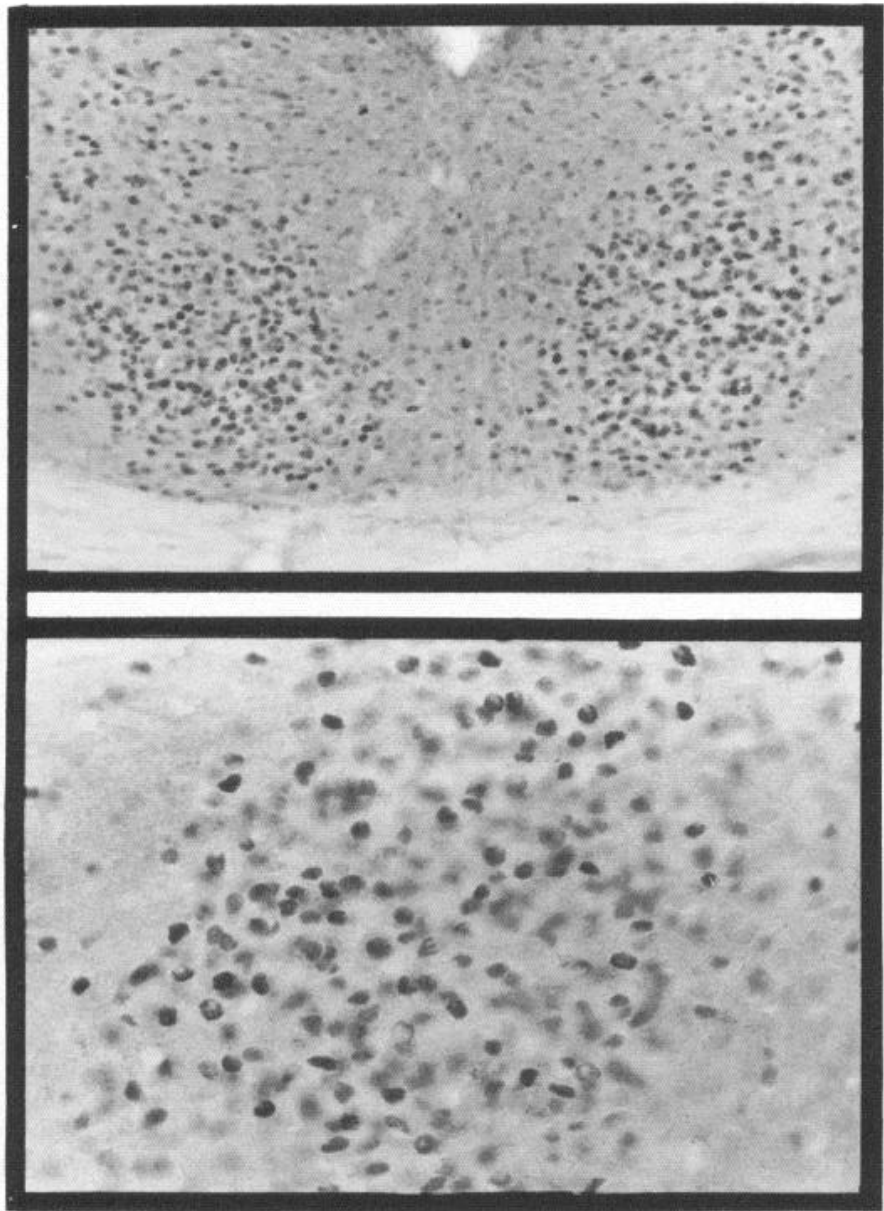

CARBACHOL

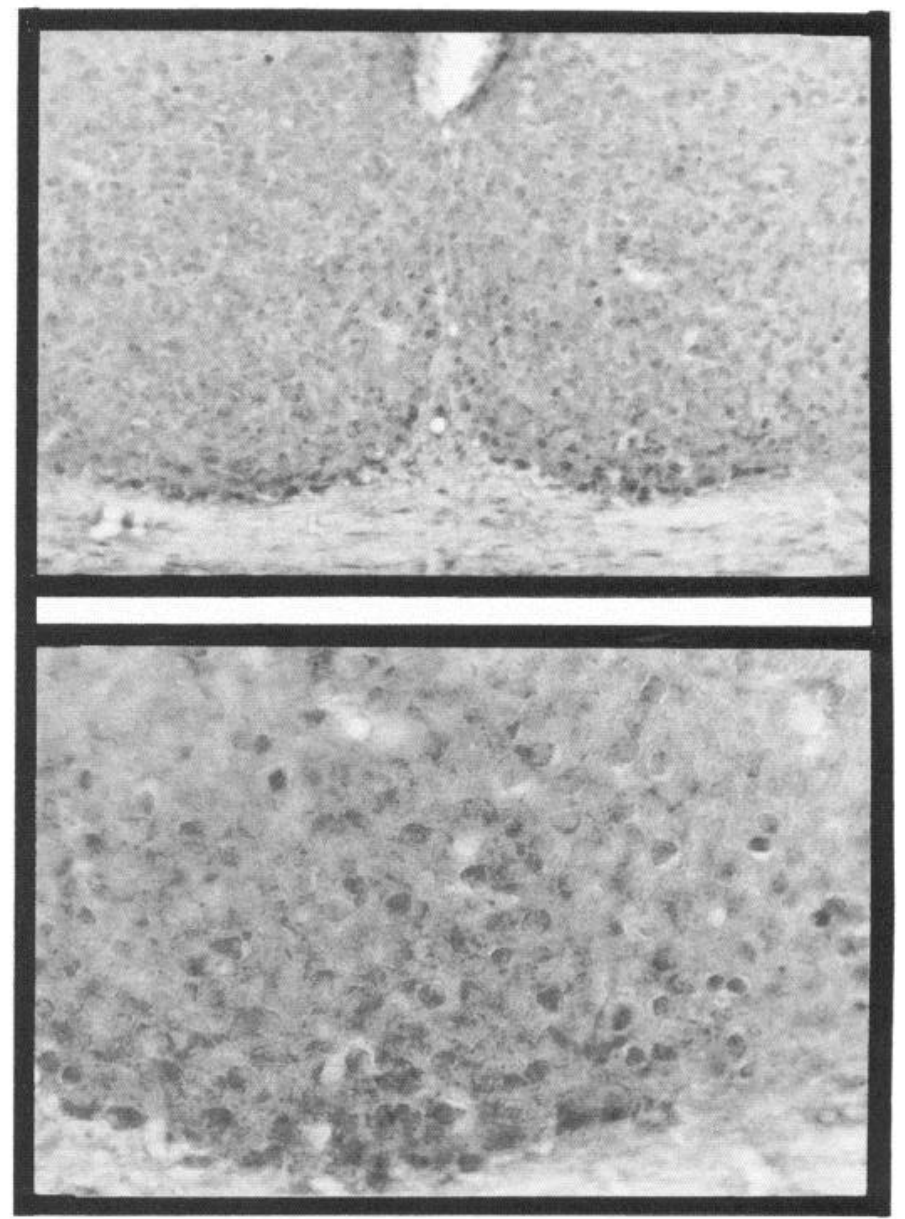

Figure 4. Photomicrographs of coronal sections through the SCN region of hamsters that have been stained for Fos-LI. Hamsters in DD either were treated with an intraventricular injection of carbachol $8 \mathrm{hr}$ after activity onset at CT 20 (right) or were exposed to 15 min of light (left). Animals were perfused $60 \mathrm{~min}$ after the treatment. Magnification: top, 200×; bottom, $400 \times$.

levels of Fos-LI that were higher than those found in the untreated controls.

\section{Discussion}

Carbachol is a nonselective cholinergic agonist that activates both muscarinic and nicotinic $\mathrm{ACh}$ receptor subclasses. In mammals, this agonist has been reported to mimic light-induced phase shifts in vivo (Zatz and Brownstein, 1979; Zatz and Herkenham, 1981; Earnest and Turek, 1983, 1985; Wee et al., 1992; also see Meijer et al., 1988, for alternative view). Both the intraventricular injection of carbachol and exposure to brief pulses of light cause phase-dependent phase shifts of the circadian system. The phase dependence of these two treatments is roughly similar; both light and carbachol applied during the early subjective night cause phase delays, whereas the same treatments administered during the late subjective night cause phase advances (DeCoursey, 1964; Earnest and Turek, 1985; Meijer et al., 1988). This similarity has led to the suggestion that carbachol acts on the light-input pathway. However, during other phases of the circadian cycle, the effects of intraventricular injection of carbachol are clearly different from those of light. Carbachol injections have consistently been found to cause phase advances at phases during the subjective day at which light pulses are without effect. Thus, although the phase shifts caused by carbachol show some similarities to those produced by light pulses during the subjective night, there are also clear differences.

Earnest and Turek (1985) and Meijer et al. (1988) have obtained different results in the phase shifts generated by carbachol treatment at CT 18. Earnest and Turek found that carbachol caused phase advances at CT 18, while Meijer and coworkers did not. In our hands, carbachol injections at CT 18 resulted in phase shifts of variable amplitude. While some animals clearly responded with phase advances, the overall group mean phase shift caused by this treatment was not significant. However, at CT 20, we found consistent phase advances to carbachol injections. Interestingly, these carbachol-induced phase shifts lacked the transients normally associated with light-induced phase advances. All of the carbachol-induced phase advances were completed by the second cycle after treatment, while completion of light-induced phase advances typically requires four or five cycles. This result is consistent with a difference in the mechanism of action between light and carbachol treatments.

A number of previous studies have shown that light causes induction of Fos protein and message in the SCN (Rea, 1989; Aronin et al., 1990; Earnest et al., 1990; Kornhauser et al., 1990; 
CARB
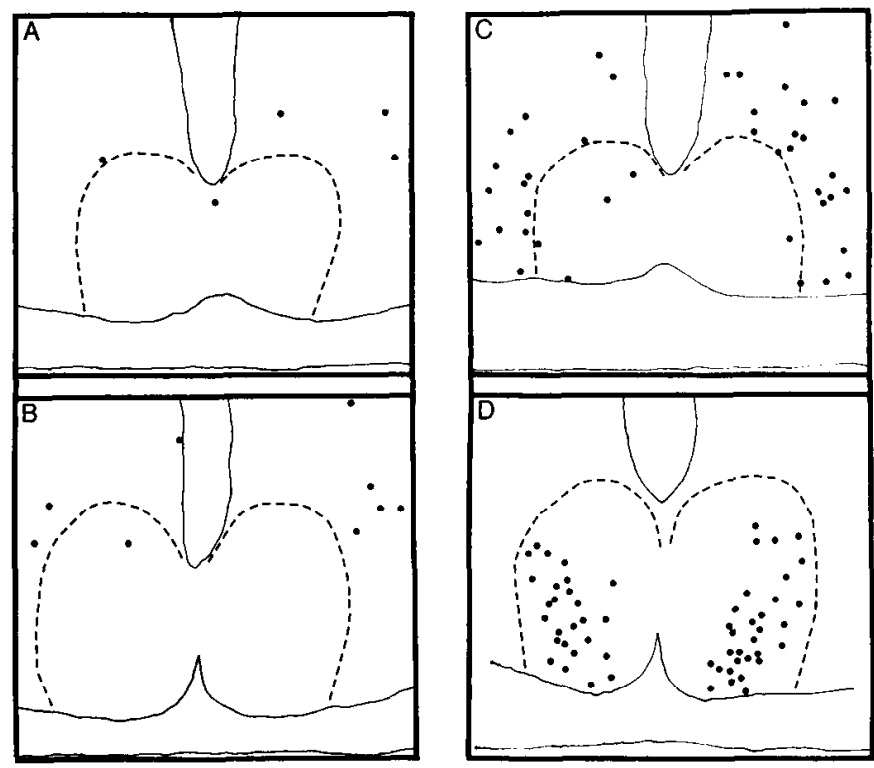

Figure 5. Schematic diagrams illustrating the distribution of Fos-LI through rostral $(A, C)$ and $(B, D)$ caudal aspects of the hamster SCN. The animal on the right $(L I G H T)$ was exposed to 15 min of light at $C T$ 20 while the animal on the left $(C A R B)$ was treated with an intraventricular injection of carbachol at the same phase. The animals were perfused $60 \mathrm{~min}$ after treatment. Immunoreactive perikarya are represented by solid dots, and the Nissl-defined SCN is shown with the dashed line.

Rusak et al., 1990; Colwell and Foster, 1991). Although the functional role of this Fos induction is not known, it does appear to be a good marker of photic stimulation of the SCN. If carbachol were acting via the light-input pathway to cause phase shifts of the circadian system, one would expect that, like light, it would cause an increase in Fos-LI in the SCN. However, this does not seem to be the case.

Our data demonstrate that it is possible to cause phase shifts of the circadian system without concomitant Fos-induction. A recent study also indicated that a nonphotic stimulus could cause phase shifts during the subjective day without also causing Fos-induction (Mead et al., 1992). The lack of effect of carbachol on Fos-LI is particularly interesting in that, like light, it causes phase shifts during the subjective night. This dissociation suggests that Fos induction may not be generally involved in phase shifting.

The neuroanatomical site of action of carbachol is unknown. The observation that this cholinergic agonist causes phase shifts suggests that it acts within the SCN or at neurons that project to the $\mathrm{SCN}$. Electrophysiological studies indicate that $\mathrm{ACh}$ is not a transmitter at the RHT/SCN synaptic connection (Shibata et al., 1986; Cahill and Menaker, 1987). Nevertheless, there is evidence that carbachol does affect the firing rate of SCN neurons (Nishino and Koizumi, 1977; Miller et al., 1982). Anatomical studies have found some evidence for both muscarinic and nicotinic cholinergic receptors being present in the SCN (e.g., van der Zee et al., 1991; but also see Clarke et al., 1985; Rusak and Bina, 1990). However, it is currently unclear whether carbachol acts directly to stimulate cholinoceptive neurons within the SCN or indirectly on neurons that project to the SCN.

The pharmacological similarities that exist between the ion channels activated by nicotinic ACh and NMDA receptors com- plicate the present study. Previous studies have shown that under certain conditions dizocilpine can antagonize both nicotinic and NMDA receptor channels (Ramoa et al., 1990; Aizenman et al., 1991; Amador and Dani, 1991). However, the receptors themselves are distinct. Competitive receptor antagonists, such as CPP, are highly selective for the NMDA receptor, having little to no effect on other receptors studied (Davies and Watkins, 1982; Lehmann et al, 1987; Childs et al., 1988). The observation that the competitive NMDA receptor antagonist CPP can block carbachol-induced phase shifts makes it unlikely that the actions of the NMDA receptor antagonists could be explained through a nonselective blockade of $\mathrm{ACh}$ receptors.

Our results with dizocilpine and CPP demonstrate that NMDA receptor antagonists can block the phase-shifting effects of carbachol. Previous studies have found that these antagonists block light-induced phase shifts and suggest that the RHT/SCN synaptic connection is the likely site of action (Colwell et al., 1990, 1991; Mason and Rusak, 1990; Kim and Dudek, 1991; Colwell and Menaker, 1992). In a simple model of the circadian system, light causes a linear cascade of events resulting in a phase shift of the circadian pacemaker. If carbachol acts via this light-input pathway to cause phase shifts, then our data indicate that it must act at a point in such a cascade that occurs before the $\operatorname{step}(\mathrm{s})$ blocked by the EAA receptor antagonists. Alternatively, carbachol-induced phase shifts may be mediated by an entirely different pathway than that which underlies light-induced phase shifts. This is perhaps the simplest explanation for the data presented in this article. It is supported by (1) the difference in phase dependence of the two treatments, (2) the difference in observed transients after treatment, and (3) the observation that carbachol does not cause induction of Fos-LI in the SCN. Alternatively, if carbachol is acting via the light-input pathway, then it must do so by a mechanism independent of Fos induction in the SCN. In either case, elucidating the mechanisms by which carbachol acts in the circadian system may provide novel insights into the cellular mechanisms by which phase shifts are generated.

\section{References}

Abe H, Rusak B, Robertson HA (1991) Photic induction of Fos protein in the suprachiasmatic nucleus is inhibited by the NMDA receptor antagonist MK-801. Neurosci Lett 127:9-12.

Abe H, Rusak B, Robertson HA (1992) NMDA and non-NMDA receptor antagonists inhibit photic induction of Fos protein in the hamster suprachiasmatic nucleus. Brain Res Bull 28:831-835.

Aizenman E, Tang LH, Reynolds IJ (1991) Effects of nicotinic agonists on the NMDA receptor. Brain Res 551:355-357.

Amador M, Dani JA (1991) MK-801's inhibition of nicotinic acetylcholine receptor channels. Synapse 7:207-215.

Aronin N, Sagar SM, Sharp FR, Schwartz WJ (1990) Light regulates expression of a Fos-related protein in rat suprachiasmatic nuclei. Proc Natl Acad Sci USA 87:5959-5962.

Cahill GM, Menaker M (1987) Kynurenic acid blocks suprachiasmatic nucleus responses to optic nerve stimulation. Brain Res 410:125-129.

Cahill GM, Ralph MR, Menaker M (1989) Effects of excitatory amino acid receptor antagonists and agonists on suprachiasmatic nucleus responses to retinohypothalamic tract volleys. Brain Res 479:76-82.

Childs AM, Evans RH, Watkins JC (1988) The pharmacological selectivity of three NMDA antagonists. Eur J Pharmacol 145:81-86.

Clarke PBS, Schwartz RD, Paul SM, Pert CB, Pert A (1985) Nicotinic binding in the rat brain: autoradiographic comparison of $\left[\mathrm{H}^{3}\right]$ acetylcholine, $\left[\mathrm{H}^{3}\right]$ nicotine and $\left[\mathrm{H}^{3}\right]$ bungarotoxin. $\mathrm{J}$ Neurosci 5:1307-1315.

Colwell CS, Foster RG (1991) The NMDA receptor antagonist MK801 inhibits light-induced changes in Fos-like immunoreactivity in the mouse suprachiasmatic nucleus. Soc Neurosci Abstr 17:668.

Colwell CS, Foster RG (1992) Light's regulation of Fos-like immuno- 
reactivity in the suprachiasmatic nucleus of the mouse. J Comp Neurol 324:135-142.

Colwell CS, Menaker M (1992) The excitatory amino acid antagonists CPP and DNQX prevent light-induced phase shifts of the circadian rhythm of locomotor activity in the golden hamster. J Biol Rhythms 7:125-136.

Colwell CS, Ralph MR, Menaker M (1990) Do NMDA receptors mediate the effects of light on circadian behavior? Brain Res 523: 117-120.

Colwell CS, Foster RG, Menaker M (1991) NMDA receptor antagonists block the effects of light on circadian behavior in the mouse. Brain Res 554:105-110.

Davies J, Watkins JC (1982) Actions of $D$ and $L$ forms of 2-amino-5phosphonovalerate and 2-amino-4-phosphonobutyrate in the cat spinal cord. Brain Res 235:378-382.

DeCoursey PJ (1964) Function of a light response rhythm in hamsters. J Cell Comp Physiol 63:189-196.

Earnest DJ, Turek FW (1983) Role for acetylcholine in mediating effects of light on reproduction. Science 219:77-79.

Earnest DJ, Turek FW (1985) Neurochemical basis for the photic control of circadian rhythms and seasonal reproductive cycles: role for acetylcholine. Proc Natl Acad Sci USA 82:4277-4281.

Earnest DJ, Iadarola M, Yeh HH, Olschowka JA (1990) Photic regulation of c-fos expression in neural components governing the entrainment of circadian rhythms. Exp Neurol 109:353-361.

Ebling FJP, Maywood ES, Staley K, Humby T, Hancock DC, Waters CM, Evan GI, Hastings MH (1991) The role of $N$-methyl-D-aspartate type glutamatergic neurotransmission in the photic induction of immediate-early gene expression in the suprachiasmatic nuclei of the Syrian hamster. J Neuroendocrin 3:641-652.

Foster RG, Provencio I, Hudson D, Fiske S, De Grip W, Menaker M (1991) Circadian photoreception in the retinally degenerate mouse (rd/rd). J Comp Physiol 169:39-50.

Ito C, Wakamori M, Akaike N (1991) Dual effect of glycine on isolated rat suprachiasmatic neurons. Am J Physiol 260:C213-C218.

Keefe DL, Earnest DJ, Nelson D, Takahashi JS, Turek FW (1987) A cholinergic antagonist, mecamylamine, blocks the phase shifting effects of light on the circadian rhythm of locomotor activity in the golden hamster. Brain Res 403:308-312.

Kim YI, Dudek FE (1991) Intracellular electrophysiological study of suprachiasmatic nucleus neurons in rodents: excitatory synaptic mechanisms. J Physiol (Lond) 444:269-287.

Kornhauser JM, Nelson DE, Mayo KE, Takahashi JS (1990) Photic and circadian regulation of c-fos gene expression in the hamster suprachiasmatic nucleus. Neuron 5:127-134.

Lehmann J, Schneider J, McPherson S, Murphy DE, Bernard P, Tsai C, Bennett DA, Pastor G, Steel DJ, Boehm C, Cheney DL, Liebman JM, Willaims M, Wood PL (1987) CPP, a selective $N$-methyl-Daspartate-type receptor antagonist: characterization in vitro and in vivo. J Pharmacol Exp Ther 240:737-746.

Mason R, Rusak B (1990) NMDA-evoked responses in the Syrian hamster suprachiasmatic nucleus in vitro. J Physiol (Lond) 435:39.

Mead S, Ebling FJP, Maywood ES, Humby T, Herbert J, Hastings MH (1992) A nonphotic stimulus causes instantaneous phase advances of the light-entrainable circadian oscillator of the syrian hamster but does not induce the expression of c-fos in the suprachiasmatic nuclei. J Neurosci 12:2516-2522.

Meijer JM, van der Zee EA, Dietz M (1988) The effects of intraventricular carbachol injection on the free-running activity rhythm of the hamster. J Biol Rhythms 3:333-348.

Miller JD, Murakami DM, Fuller CA (1987) The response of suprachiasmatic neurons of the rat hypothalamus to photic and nicotinic stimuli. J Neurosci 7:978-986.
Moffett JR, Williamson L, Palkovits M, Namboodiri MAA (1990) Nacetylaspartylglutamate: a transmitter candidate for the retinohypothalamic tract. Proc Natl Acad Sci USA 87:8065-8069.

Moore RY (1983) Organization and function of a central nervous system circadian oscillator: the SCN. Fed Proc 42:2783-2789.

Morgan JI, Curran T (1991) Stimulus-transcription coupling in the nervous system: involvement of the inducible proto-oncogenes Fos and Jun. Annu Rev Neurosci 14:421-451.

Murakami N, Takahasi K, Kawashiwa K (1984) Effect of light on the acetylcholine concentrations of the suprachiasmatic nucleus in the rat. Brain Res 311:358-360.

Nelson RJ, Zucker I (1981) Absence of extraocular photoreception in diurnal and nocturnal rodents exposed to direct sunlight. Comp Biochem Physiol [A] 69:145-148.

Nishino H, Koizumi K (1977) Responses of neurons in the suprachiasmatic nuclei of the hypothalamus to putative neurotransmitters. Brain Res 249:167-172.

Ramoa AS, Alkondon M, Aracava Y, Irons J, Lunt GG, Deshpande SS, Wonnacot S, Aronstam RS, Albuquergue EX (1990) The anticonvulsant MK-801 interacts with peripheral and central nicotinic acetylcholine receptor ion channels. J Pharmacol Exp Ther 254:7182.

Rca MA (1989) Light incrcascs Fos-related protein immunoreactivity in the rat suprachiasmatic nuclei. Brain Res Bull 23:577-581.

Rea MA, Buckley B, Michel AM, Lutton LM (1991) Local administration of CNQX attenuates light-induced phase advances of the circadian activity rhythm and Fos expression in the hamster SCN. Soc Neurosci Abstr 17:668.

Rusak B, Bina KG (1990) Neurotransmitters in the mammalian circadian system. Annu Rev Neurosci 13:387-401.

Rusak B, Robertson HA, Wisden W, Hunt SP (1990) Light pulses that shift rhythms induce gene expression in the suprachiasmatic nucleus. Science 248:1237-1240.

Shibata S, Liou SY, Ueki S (1986) Influence of excitatory amino acid receptor antagonists and of baclofen on synaptic transmission in the optic nerve of the suprachiasmatic nucleus in slices of rat hypothalamus. Ncuropharmacology 25:403-409.

Takahashi JS, DeCoursey PJ, Bauman L, Menaker M (1984) Spectral sensitivity of a novel photoreceptive system mediating entrainment of mammalian circadian rhythms. Nature 308:186-188.

Takeuchi Y, Takashima M, Katoh Y, Nishikawa T, Takahashi K (1991) $N$-methyl-D-aspartate, quisqualate and kainate receptors are all involved in transmission of photic stimulation in the suprachiasmatic nucleus in rats. Brain Res 563:127-131.

Van den Pol A (1991) Glutamate and aspartate immunoreactivity in hypothalamic presynaptic axons. J Neurosci 11:2087-2101.

van der Zee EA, Streefland C, Strosberg AD, Schroder H, Luiten PGM (1991) Colocalization of muscarinic and nicotinic receptors in cholinoceptive neurons of the suprachiasmatic region in young and aged rats. Brain Res 542:348-352.

Wee BEF, Anderson KD, Kouchis NS, Turck FW (1992) Administration of carbachol into the lateral ventricle and suprachiasmatic nucleus ( $\mathrm{SCN}$ ) produces dose-dependent phase shifts in the circadian rhythm of locomotor activity. Neurosci Lett 137:211-215.

Zatz M, Brownstein MJ (1979) Intraventricular carbachol mimics the effects of light on the circadian rhythm in the rat pineal gland. Science 203:358-361.

Zatz M, Herkenham MA (1981) Intraventricular carbachol mimics the phase shifting effects of light on the circadian rhythm of wheelrunning activity. Brain Res 212:234-238. 